\title{
Automation ANXIETIES AND INFRASTRUCTURAL TECHNOLOGIES
}

\section{Andrew Goffey}

\begin{abstract}
Contesting binaries that tend to underlie claims about automation, this article seeks to complicate arguments that are made about digital technology and the processes and practices of automation essential to it. In particular, it contests a well-entrenched distinction between infrastructures and culture, so as to consider more carefully the relationship between processes and practices of automation distributed throughout the increasingly planetary web of digital infrastructures, and subjectivity. Rather than viewing the logic of automation through the lens of value extraction, the paper links post-Foucauldian arguments about governmentality and the production of subjectivity to the strategic origins of computation in war, on the one hand, and processes and practices of infrastructure production on the other. This in turn facilitates a more nuanced, micropolitical, view of the grey area of human-machine relations worked on by automation.
\end{abstract}

Keywords: automation, governmentality, infrastructure, machinic enslavement, micropolitics, strategy

\section{INTRODUCTION}

According to the pundits, business school apologists, management consultants and Silicon Valley boosters, people whose stock in trade is performative commenting on business trends, we are living in the era of the rise of the robots. Anyone with a memory might be forgiven for thinking that this is not news. The art of presenting history in terms of broad-brush abstractions information, technology, artificial intelligence - and offering only the most cursory analysis (if at all) of the failings of previous grand predictions, whether the revolution promised is apocalyptic or utopian, has accompanied the development of the computer more or less since its inception. But this time, we are told, the automation in question is 'different'. In curiously imperative language, we are also told, it is time to 'be afraid'. ${ }^{1}$ Perhaps because this time it is a stratum of more professional white collar jobs (not lowly clerical work or blue collar manual labour) that are on the line, there is indeed a difference, but of tone perhaps, not dynamic. The highly selective correlations, between technology investment and productivity, remain largely the same and the analysis is no less beholden to the powerful modernising tropes of economistic progressivism, but the importuning is that bit more hysterical. Technology,

1. Martin Ford, The Rise of the Robots, London, Oneworld, 2015 , is a good example of the genre. 
2. Jennifer Bayot, 'John Diebold, 79, a Visionary of the Computer Age, Dies' New York Times 27/12/2005 online at: https:// www.nytimes. com/2005/12/27/ nyregion/johndiebold-79-avisionary-of-thecomputer-age-dies. html.

3. David F. Noble, Forces of Production. A Social History of Automation, New Brunswick NJ, Transaction, 2011; Nick DyerWitherford CyberProletariat: Global Labour in the Digital Vortex, London, Pluto, 2015, chapter 3.

4. Luciano Floridi, The Fourth Revolution, Oxford, Oxford University Press, 2014, p3.

5. See for example the reports produced by TechRepublic, https:// www.techrepublic. com/article/ it-project-failurescostly-techrepublicgartner-study-finds/ (accessed 1 October, 2019).

6. Nathan Ensmenger, The Computer Boys Take Over, Cambridge MA, MIT Press, 2010.

7. Michael S.

Mahoney, 'Computer Science. The Search for a Mathematical Theory' in J. Echeverria, A. Ibarra and T. Mormann (eds), The Space of Mathematics, Berlin, De Gruyter, 1992, p358. in the abstract, is still the driver and adaptation to it still the solution.

Claims that digital technology will 'revolutionise' the world have been a recurrent feature of the discourse around computers and computerisation since the Second World War. Sometimes such claims are framed precisely in terms of computers and computerisation, at others in much broader terms. The writings of John Diebold, author of a 1952 book on Automation: the Advent of the Automatic Factory and characterised in a New York Times obituary, in 2005 as a 'visionary of the computer age' might stand as a good example of the genre, framing information and communication as the 'very core' of human society and predicting great progress. ${ }^{2}$ But he's not the only one, and the arguments cut both ways: Norbert Weiner, for example, was already predicting in 1949, the replacement of the mass worker by the 'automatic assembly line', not without justification. ${ }^{3}$ Claims for epochal transformation have spawned much futurological prognostication not just in managerial discourse, policy circles, and tech publications, but also in the social sciences, in political theory and philosophy, where Teilhard de Chardin-type cosmic evolutionism is palpable, in arguments for a 'fourth' revolution. History, it has been claimed, is 'synonymous with the information age'. ${ }^{4}$

Yet for every successfully functioning technoscientific apparatus, in every new 'wave' of automation, there are always others that fail. For every globally successful platform there are dozens - start-ups and projects alike - that fall by the wayside. IT project failure - some reports suggest, conservatively, an average 40 per cent failure rate per annum ${ }^{5}$ - itself is big business and 'crisis' seems to be built into the history of the software industry. ${ }^{6}$ For every new, heavily promoted development in AI, there are the myriad false steps - technical and epistemic, theoretical and practical - of AI in the past, with nothing like a 'normal science' ever having been established, just a loose set of postulates about intelligence and an appeal to the Turing 'test'. Theorists can and do claim paradigmatic status for technological or economic development, as well as for science, but usually on the basis of a rather selective reading of Kuhn's work. The production of textbooks and consensus amongst computer scientists or AI practitioners isn't really enough to turn something into a science. Indeed, as the historian of computer science Michael Mahoney has pointed out, discussing a 'state of the field' report from 1975 entitled 'What can be automated?' the 'fundamental mathematical questions' that computer science asked 'tended to follow developments in technology and its application' and hence presuppose that technology's existence. ${ }^{7}$

This is not to say that computer-based automation, of the AI-kind, doesn't employ often very sophisticated forms of scientific knowledge. But it does mean that analysis has to be rather more circumspect about 'fundamental' claims and what they overlook than the recurrent appeal to the 'paradigm' suggests. Journalists and others can - and do - give contemporary technology the allure of fate by projecting 'information' back into the mists of time, but this doesn't stop the appeal of their narratives (like those of other pop science 
proselytising on behalf of neo-Darwinism) to the 'hard truths' of technoscience from being covertly first-world-centric teleology. In stories about the rise of the robots considerable attention is usually given to carefully selected, excessively decontextualised examples, a move symptomatic of the broader forgetting of what Gray and Suri refer to as the 'ghost work' that transforms artificial intelligence into artificial artificial intelligence, the smoke and mirrors of Amazon's Mechanical Turk. ${ }^{8}$ In any case, much less attention is paid to the more mundane apparatuses of automation which facilitate the growing encroachment of large technology corporations on everyday life, on what's left, in the global North, of the institutions of the welfare state, and on the privacy of the individual. Automation at an infrastructural level, sometimes euphemised as 'unbundling', an efficacious tactic in the strategic re-aligning of public and private interest, goes uncommented, at least until 'lock-in' makes reversing transformations impossible, as contemporary concerns about the 'automation of the welfare state' suggest.

Undoubtedly the noisiest, and perhaps most seductive, elements of the post-war discourse on computers and automation through and of information technology have concerned the transformation of work. But it is also necessary to note the presence, alongside the media discourse amplifying the futurology that has persistently accompanied the growth of IT, of a voluble concern about other aspects of this development, specifically now 'internet addiction'. Whilst still not in the prescribers' bible, the DSM, and like its equally nebulous sibling 'technology addiction', internet addiction raises the spectre of another kind of automation. Not automation of the 'transformation of work by machines' kind but automatism of the compulsive, binding of drive energy, psychic kind. Routinely glossed in terms of generic, quasi-scientific 'dopamine hit' based explanations, this other kind of automation, often linked to scare stories about the online gaming habits of young men, communicates also with a recent spate of stories about repentant West Coast technologists, now pleading in favour of humane technology. 'Our' addiction to technology, the stories run, is then transformed into a narrative of psychological balance versus corporate greed. Analysis of the broader assemblages of which ostensibly addictive technologies are a part, and of the ways in which humans are incorporated into such apparatuses more generally, then tends to disappear, effectuating a kind of amnesia about technological history. The transformation of the computer as element of managerial technocracy into instrument of personal liberation, explored by Fred Turner, extends finally into a symptom of individualised, neurochemical, failure. ${ }^{9}$

Crude though it is, juxtaposing different kinds of scare stories about digital technology can highlight something of the complexities with which an analysis of contemporary automation anxiety, or anxieties, has to contend, and it raises questions about the manner in which discourses about specific technologies draw on broader features of thinking within modernity. The separation of compulsion/addiction concerns from rise of the robots futurology, as expressed
8. Mary L. Gray and Siddharth Suri, Ghost Work. How to Stop Silicon Valley from Building a New Global Underclass, New York, Houghton Mifflin Harcourt, 2019.

9. Fred Turner, From Counterculture to Cyberculture, Chicago IL, University of Chicago Press, 2006. 
10. Gilles Deleuze and Félix Guattari, Anti-Oedipus, Minneapolis, University of Minnesota Press, $1983, \mathrm{p} 104$.

in Anglophone media, in particular, echoes the institutional entrenchment of dualistic thinking of the subject-object kind: objective transformation of the economic sphere of work, subjective transformation of the individual, particularly in the context of leisure activities. But that division leaves far too many questions about automation, what 'it' is, how it functions, unanswered. In this respect, and as a variant form of the moral panics that traditional media excel in generating, automation anxieties confirm, a bit too easily, a more general understanding of automation that continues to dissociate digital technological infrastructures and symbolic, subjective cultures.

It is the contention of this essay, by contrast, that analysing the transformations associated with digital technological automation must ultimately be undertaken in terms of a problematic of the production of subjectivity for which it (automation) has become one of the crucial vectors. A problematic that emerges out of the work of Félix Guattari in particular, addressing subjectivity as produced entails viewing it as immanent to socioeconomic configurations, it entails seeing drive energies, affective dispositions and configurations not as a sort of epiphenomenal add-on to broader processes but as an integral part of them in their complex, variegated materiality. Whilst it seems a bit glib now, Guattari's claim that 'desire is part of the infrastructure' captures well a crucial characteristic of thinking in terms of the production of subjectivity: challenging the well-entrenched intellectual habit of thinking in terms of the subject-object division, even in the intimate recesses of the unconscious. ${ }^{10}$ Contemporary anxieties over automation, from this point of view, are to be understood not simply as individual responses to heavily saturated media representations of the rise of the robots, or as a medicomediatic concern with a vague neuropsychologically framed compulsion, but rather treated as indices of a determinate configuration of a social field that is increasingly planetary in scope, a social field that is less a global civil society, as new forms of liberalism might claim, and more the ongoing product of a form of governmentality that formats populations at a problematically planetary scale. This is not a conventional manner of exploring processes and practices of automation. For critical social, cultural and political thinking about automation, the allure of technoscientific eulogising tends for the most part to be replaced with analysis of the exploitative, political economic dynamic of the development of capitalism (debates over the labour theory of value figure strongly here). However, even in the most hard-headed of these accounts, some sort of variant form of the historical ruse of reason tends to inform the political consequences that are drawn from such analyses. Total automation - of intellectual and manual labour, can ultimately only be progressive. Of course, there is no mistaking the fact that automation in the contemporary era is very much a crucial economic phenomenon, that the transformation of work in recent decades, whether framed as part of a fourth revolution, a knowledge economy, the shift into cognitive capitalism, or something else, has a powerfully technological flavour. Nor is 
there any mistaking the conjunctural nature of the resurgence of concerns about automation, specifically its coinciding with post-crash austerity-based restructuring. But what is far less clear is what conclusions can reasonably be drawn from such connections. The sheer extensiveness of processes and practices of automation across digital infrastructures - so-called ubiquitous computing - and the intensity of subjective investments in such infrastructures, raises questions about technology that are not easily addressed within existing theoretical frameworks.

\section{STRATEGIC EXPERTISE}

The historical emergence of computing out of technological and scientific developments during and after the Second World is, of course, reasonably well known, its cultural complexities attested to indirectly in Donna Haraway's early work, its embedding in the paranoid narrative of the Cold War explored in Edwards' discussion The Closed World, and so on. ${ }^{11}$ Numerous historians have traced out the web of links drawing together the military, corporations and universities, the 'Iron Triangle' around which the post-war era of 'big science' inaugurating the kind of developments forming what Bell would later call 'post-industrial society'. 'Cyborg science', 'World War II regime', 'Manichean sciences' are perhaps a bit less euphemistic about the simultaneously political, military and technological qualities of the nature of the technoscientific expertise that took shape in the middle of the last century in the West. And whilst it's tempting to cherry-pick from such research to confirm broader macro-scale arguments (e.g. about domination and the instrumental rational nature of technoscience), it's actually rather difficult to separate the early development of computing from the broader sets of institutional relations, scientific and technological practices and macro-political priorities (and paranoia) of the Cold War period. There's not much that exemplifies the effects of the emergent military-industrialuniversity complex better than computation. After all, one of the biggest winners of the big science practiced at Los Alamos was the computer, which in its use to simulate the numerically highly complex behaviour of sub-atomic particles, as Galison argues, generated a transformation of scientific practices, troubling conventional distinctions between theory and experiment through its production of artificial realities (the bomb as a simulated phenomenon, in the first instance). The computer, as he puts it "began as a "tool", an object for the manipulation of machines, objects, and equations. But bit by bit (byte by byte), computer designers deconstructed the notion of a tool itself as the computer came to stand not for a tool, but for nature'. ${ }^{12}$

Oddly though, this development, which was not without a correlative transformation of the mathematicians, physicists, statisticians, engineers and others involved the mission-directed activity of the Second World War and thereafter, was also accompanied by a particular presentation of science that
11. Donna Haraway, 'A Cyborg Manifesto: Science, Technology and SocialistFeminism in the Late Twentieth Century' in Symians, Cyborgs, and Women. The Reinvention of Nature, New York, Routledge, 1991; Paul N. Edwards, The Closed World: Computers and the Politics of Discourse in Cold War America, Cambridge, MIT Press, 1996. (Hereafter Closed World).

12. Peter Galison, Image and Logic: A Material Culture of Physics, Chicago, University of Chicago Press, 1997, p777. 
13. Brian Balogh, 'Reorganizing the Organizational Synthesis: Federal Professional Relations in Modern America', Studies in American Political Development 5, 1, 1991.

14. Allen Newell and Herbert Simon,'Computer Science as Empirical Inquiry: Symbols and Search, Communications of the ACM, 19, 3, 1976.

15. Daniel Bell, The Coming of PostIndustrial Society quoted in Ronald $\mathrm{R}$. Kline, The Cybernetics Moment: Or Why We Call Our Age the Information Age, Baltimore MA, Johns Hopkins University Press, 2015, p216.

16. See in particular Paul Erickson et al, How Reason Almost Lost its Mind. The Strange Career of Cold War Rationality, Chicago IL, University of Chicago Press, 2013. Following the development of the formalist hostility towards intuition would take us into yet another history, that of the relationship between formal and natural languages and the enmity of logicians for what they saw as the slipperiness of natural language. See the brief comments on this in Matthew Fuller and Andrew Goffey, Evil Media, Cambridge MA, MIT Press, 2011, p18.

17. Will Thomas, Rational Action, Cambridge, MIT Press, 2015. was, in some respects, at odds with the troubling position of the computer in the theory-experiment-instrument hierarchy of scientific understanding. The era of 'big science' from which the development of computing is inseparable, is an era of the general mobilisation of scientific and technological research, in which scientific practices are allied to a powerfully interventionary state Balogh's 'proministrative state' - in which fundamental, or 'basic' research, presented as autonomous, as Science, the 'goose that lays the golden eggs', is linked closely to the management of society. ${ }^{13}$ The emerging technologies of computation and the practices associated with them took their place within this inter- or trans- disciplinary research formation and to a considerable extent came to frame themselves in terms of a discourse of Science (the 'endless frontier') distinguished by its capacity to address and to understand problems that the public at large could not but fail to understand.

When Allen Newell and Herb Simon, in their 1975 address to the Association of Computing Machinery, presented themselves as 'basic scientists' whose work might easily be misunderstood by the outside world - a society which 'often becomes confused' about why computers are built, which 'needs to understand' that basic research will 'pay off' in terms of new techniques - they were doing nothing other than presenting their work and its yield in technological terms quite precisely in terms of this view of scientific practices as Science. ${ }^{14}$ And in many respects, when commentators such as Daniel Bell, writing about post-industrial society, thematised the 'codification of theoretical knowledge' in 'intellectual technology' as key to the changing morphology of Western societies, they were likewise pointing precisely to an apparatus of knowledge production in which a peculiarly abstracted understanding of scientific and technical practices was configured, in which theoretical claims developed in the former explained or were the directive force for the latter. ${ }^{15}$ Referring as he does to 'new relations between theory and empiricism', Bell was transcribing the image of scientific and technological practices as Science that had been assumed by well-known figures in the emerging military-industrial complex (p216). He was also - and not incidentally - ventriloquising a view of rationality that saw the rule-based formalism of the algorithm as substituting for intuitive judgement ${ }^{16}$ in decision-making, a process that had already shown itself, albeit in a problematic way, as being crucial to the development during Second World War of what Will Thomas calls the 'policy sciences'. ${ }^{17}$ It's a view of rationality that figured very heavily too in the emerging field of 'cognitive science', which in many respects transformed psychology and its view of the individual along recognisably normative lines, as a number of commentators have argued. ${ }^{18}$ Refigured, via systems analysis and management scientists in particular, as 'information technology' in the late 1950s, such thinking was already promising revolutionary transformations, specifically in terms of facilitating the emergence of top-down managerial control. Early theorists, for example, quite specifically drew an analogy between the manner in which IT would allow top layers of management to control middle management, "just 
as Taylorism allowed the middle to control the bottom' $\cdot{ }^{19}$ One cannot - should not-overlook the fact that much of the impetus for computational automation, in the guise of information technology, was (and remains) administrative. It's not for nothing that Jon Agar has referred to the computer as the government machine, even if that has proved rather easy to forget. ${ }^{20}$ It is via the office (or, metonymically, via Office, now with us 365 , if one wanted to trace the history through software), automating discourse production specifically, more than the factory, that computing tends to enter everyday life, and whilst this is something that can be framed in terms of value extraction, there is a risk here that doing so can result in an analysis that not only not only leaves in the background or simplifies out to the point of irrelevance, numerous aspects of technological development, the how of automation, but that one also takes as a given - the successful and effective functioning of specific forms of technology - something that is in fact far more contingent and experimental.

There are a complex set of strategic considerations at work in the development of the processes and practices of automation marking the post-war era. In this regard, it is worth considering a bit more carefully the practical field of relations in terms of which the growing interest in and practice of technoscientific automation emerged. In his essay on Norbert Wiener, cybernetics and the 'ontology of the enemy', Peter Galison makes a powerful case for considering a number of wartime scientific developments concerned precisely with the machine-human systems (and the automation that characterised them) central to the ulterior developments around computation - operations research, game theory and cybernetics - as 'Manichean' sciences, predicated on a 'particular kind of enemy', one who was 'at home in the world of strategy, tactics, and manoeuvre, all the while thoroughly inaccessible to us, separated by a gulf of distance, speed, and metal' ${ }^{21}$ Elaborating on the manner in which Wiener's work on a device designed to predict the zig-zagging nature of an enemy pilot's flight morphed into cybernetics more generally, what comes to the fore in Wiener's work - and it is a feature, Galison argues, that it shares with operations research and game theory - is a tacit but profound sense of the universe as shaped through a confrontation of opponents: developing initially through a conceptualisation of the enemy pilot (and then the friendly pilot) as a servomechanism that would facilitate the anticipation of his intentions (and so permit his destruction through an automated firing mechanism), the cybernetic approach to automation implied a universe split between 'us' and the inherently, necessarily crafty, machine-like Other.

In fighting this cybernetic enemy, Wiener and his team began to conceive of the Allied anti-aircraft operations as resembling the foe, and it was a short step from this elision of the human and the non-human in the ally to a blurring of the human-machine boundary in general. The servomechanical enemy became, in the cybernetic vision of the 1940s, the protoype for human physiology and, ultimately, for all of human nature ... (p233).

For Galison, the problem that this ontology of the enemy that he
18. This issue has been explored in different ways by Hunter CrowtherHeyck, Herbert $A$. Simon: The Bounds of Reason in Modern America, Baltimore, MA, Johns Hopkins University Press, 2005; Jamie CohenCole, The Open Mind: Cold War Politics and the Sciences of Human Nature, Chicago, University of Chicago Press, 2014.

19. Harold Leavitt and Thomas Whisler, quoted in Kline op. cit., p205.

20. Jon Agar, The Government Machine, Cambridge, MIT Press, 2003.

21. Peter Galison, 'The Ontology of the Enemy: Norbert Wiener and the Cybernetic Vision' in Critical Inquiry, 21,1, 1994, pp.228-266, p233. 
22. Most recently in Éric Alliez and Maurizio Lazzarato, Wars and Capital, Los Angeles CA, Semiotext(e), 2018. (Hereafter Wars and Capital).

23. Gordon Pask, quoted in Geoffrey Bowker 'How to be Universal: Some Cybernetic Strategies, 1943 70', Social Studies of Science 23, 1993, pp107-127, p122.

24. George A. Reisch, How the Cold War Transformed Philosophy of Science: To the Icy Slopes of Logic, New York, Cambridge University Press, 2005; Philip Mirowski, 'The scientific dimensions of social knowledge and their distant echoes in twentiethcentury American philosophy of science', Stud. Hist. Phil. Sci. 35, 2004 pp283-326. reconstructs from Wiener's work raises is one of (enduring) cultural meanings, of a chain of discursive associations which, as he puts it, was 'forged over decades in the laboratory, on the battlefield, in the social sciences, and in the philosophy of cybernetics'. Whilst (he acknowledges) there is nothing that logically compels acceptance of the ontology tacit in cybernetics, we do have to acknowledge "the power of a half-century in which these and other associations have been reinstantiated at every turn' (p265). Here perhaps begins the recurrent invocation of cybernetics as political technology. ${ }^{22}$ But there is perhaps something here that goes beyond the simple matter of cultural associations, something that might give a bit more weight to arguments about the configuration of human-machine systems as governmental apparatus, as a 'system of generalised enslavement', as Alliez and Lazzarato put it (p236). The configuration of the war-time laboratory scene, in which strategy dictates that the agent whose behaviour is being modelled is of necessity precluded from responding to and/or taking an interest in the questions that the scientist asks of him, is indicative of a process of abstraction, on the part of the scientist and technician, from which any feedback (from the enemy/organism) is excluded. In a strategic relationship of enmity, what one wants to know about one's enemy is what his or her weaknesses are: giving your enemy the latitude to contest your appraisal of them is fatal. From this point of view, one might argue that the automated control promised by the increasingly popular cybernetics was linked as much to a practice of abstraction as it was to a theory of black-boxes and feedback loops. From this point of view, the interest in and popularity of cybernetics, theorised as 'the' (quasi-solipsistic) science of control may also have something to do with the way in which it was organised as a technoscientific practice. In this respect, the configuration of systems in terms of black-boxing and feedback loops is not just linked to the manner in which this facilitates the development of transferable machinically real abstractions (whereby - as Gordon Pask put it "precisely the same arrangement of parts in the computer can represent the spread of an epidemic, the spread of rumours in a community, the development of rust on a piece of galvanised iron and diffusion in a semi-conductor') but also the constitution of the distance at which it is possible to hold its objects. ${ }^{23}$ What Bell later conceptualised as intellectual technologies are in many respects the fruit of a profoundly antidemocratic movement in knowledge production, as Reisch and Mirowski, commentating on early post-war conceptions of science, have pointed out. ${ }^{24}$

Modelling humans in terms of the machinic configurations of servomechanisms doesn't just involve a characterisation of what is being modelled in terms of an ontology of the enemy. It is predicated on the preclusion, which is institutionally, procedurally, organised of any interest on the part of organism whose behaviour is being modelled (on threat of death). The processes and practices of automation that develop in the theory-led world of early systems thinking characteristic of post-war computerisation form part of a concrete, practical configuration that necessarily entails a 
minorisation or disqualification of forms of knowledge that conflict with the strategic aims of the system in question. This is what hostility towards 'empiricism' (already well-entrenched in the formal logician's mistrust of natural language) entails in practice. It is an issue that can be confirmed by some of the arguments that David Noble makes in the context of his discussion of the automation of production in the early post-war period in the US. Although he frames the issue in terms of a classic understanding of power, where technical people internalise the hierarchical values of their patrons (C. Wright Mills' 'technical lieutenants of power') a process which in turn informs their sense of what is possible, he points, indirectly, to the ways in which the organisation of technical laboratory practice is linked to the strategic concerns of military-industrial institutions.

If an engineer were to come up with a design for a new technical system which required for its optimal functioning considerable control over the behaviour of his fellow engineers in the laboratory, the design would be dismissed as ridiculous, however elegant and up-to-date its components. But if the same engineer created the same system for an industrial manager or the Air Force and required, for its successful functioning, control over the behaviour of industrial workers or soldiers (or even engineers in their employ), the design might be deemed viable, even downright ingenious. ${ }^{25}$

Avowedly Taylorist in inspiration, early work addressing the pragmatics of computing technology spoke, with a straight face, about 'algorithmised people'. ${ }^{26}$

It's not a question here, vis à vis the ontology of the enemy, of suggesting that computational automation of the human-machine system kind is inherently military. However, it has been a little too easy, in the history and historiography, of computing, to bracket out the military element, splitting war and economy, with the former usually understood as an interruption of the latter, thereby facilitating a presentation of computing in terms of the telos of consumer electronics. This, in turn, obscures the strategic dimensions of technology production and the power relations of which it is the bearer. Allied to this it is of course also impossible to ignore the role of the State in this period. Not just in the sense that one might, like Mariana Mazzucato, want to call into question the politically useful but economically disabling (from a policy point of view) fiction of 'public - bad, private - good', or, indeed, point towards the inordinately important role of war and the preparation for it in the success of Silicon Valley. ${ }^{27}$ More significantly, from the point of view of the ongoing organisation of relations between practices, it was precisely in its role as facilitating the constitution and coordination professional expertise, in relation to 'Science' that the State operated. Gilles Deleuze was not wrong to remind us that the State has always relied on an image of thought.
25. David F. Noble, Forces of Production. A Social History of Automation, New Brunswick, Transaction, 2011, p44.

26. Saul Gorn 'Some Basic Terminology Connected With Mechanical Languages and Their Processors', Communications of the ACM 4, 1961.

27. See, respectively, Mariana Mazzucato, The Entrepreneurial State, London, Anthem, 2014; and Stuart W. Leslie, "The Biggest "Angel" of Them All' in Martin Kenney (ed.), Understanding Silicon Valley, Stanford CA, Stanford Business Books, 2000. 
Contemporary processes and practices of automation extend well beyond selectively framed, headline-grabbing, stories about robots and/or artificial intelligence. Automation today is not, as one would sometimes be forgiven for thinking, simply a particular trend in the use of digital technology, nor is it equivalent to the cybernetisation (or 'cybernation', as 1960s commentators sometimes theorised it) of society. It cannot simply be read off in some sort of unbroken continuity with developments during the Cold War, and nor can it now be confined to the work of dedicated professional expertise. It's worth remembering that the existence of computation in the modern sense as such is predicated on the possibility of automation, on the possibility of there being 'effective procedures' that operate in conformity with the mathematical logic elaborated initially by Alan Turing. It's not just that there would be no point in programming a machine if automation in this sense was impossible: programming computers as such would be impossible. Automation is also predicated on its desirability, a point that is perhaps more easily forgotten. But more important than this is the fact that any activity accomplished through digital technology in the present presupposes a complex, ramified history of processes and practices of automation, some, but not all of which are computational: undersea cables, punch cards, hand calculated firing tables, Monte Carlo simulations, and so on. The material traces of these histories are sedimented and stratified in the plural, multi-layered, infrastructures of computation as a now planetary phenomenon. In this sense infrastructures form a material memory and constraining force without which further automation and the technological 'disruption' it is often purported to accomplish would itself be impossible. Given this, representations of computational technologies as breaking with the past (modernising to 'stay relevant' as one report from management consultants PWC put it) are simply mendacious. Disruption in the field of digital technology presupposes the very much undisrupted stability of a complex, historically and geographically specific set of infrastructures, marked by processes of marginalisation, disqualification and destruction.

Aside from the oddly overlooked issue of temporality, the reference to infrastructure here is important as it helps point up a number of key characteristics of contemporary processes and practices of automation. One is the extent to which computation has saturated everyday life, shaping expectations and (literally) providing the grounds for an understanding of the world. For many people in significant parts of the global North, infrastructure has come to be synonymous with a particular set of scarcely articulated feelings about the workings of society. As Paul N. Edwards put it (prior to the widely publicised infrastructure collapses in America in 2005) they are 'largely responsible for the sense of stability of life in the developed world, the feeling that things work, and will go on working, without the need for 
thought or action on the part of users beyond paying the monthly bills'.$^{28} \mathrm{In}$ this respect, the smooth, ostensibly friction-free availability of infrastructure may be considered in terms of a certain normalising power, operating at a particularly quotidian level shaping expectations and which acts, in turn, as the ground for judgements typical of modernity: the sense that other geographical spaces don't work, are backward. The counterpart of ubiquitous infrastructures is the peculiarly habitual quality of entanglement with them. Another key point about the infrastructural dimension of automation is the extent to which automation as process and as product operates more or less invisibly, in a quasi-naturalised space-time. Edwards, once again, observes that "the most salient characteristic of technology in the modern (industrial and post-industrial) world is the degree to which most technology is not salient for most people, most of the time' (p188). '[M]ature technological systems', he goes on 'reside in a naturalised background, as ordinary and unremarkable to us as trees, daylight, and dirt' (p185). Bruce Mau goes a step further, suggesting, with some exaggeration, that the 'intensely developed infrastructures' through which we (in the global North) live our lives have achieved a sort of 'design nirvana', accomplishing the secret ambition of design, which is, he suggests, to become 'invisible'. ${ }^{29} \mathrm{~A}$ third, key point is that framing digital technologies as infrastructural renders evident their crucial strategic status. The strategic centrality of infrastructures per se is not new. In one way or another, infrastructures have always been a crucial element in the politics of nation states, indeed, in the shaping of something like a governable nation state in the first place. Without the meticulous coordination - via the electric telegraph - that was required for railway systems to run effectively, for example, no territorially unified organisation of time was possible (see more broadly David S. Landes Revolution in Time). ${ }^{30}$ The 'technologies of freedom' that were so crucial to the enabling practices of liberal governmentality in the nineteenth century - multiplying exchanges across a unified space - imply in turn the role of infrastructures necessary to the maintenance of colonial rule, just as digital infrastructures are now crucial to the transformation of the nation state. Indeed, the conceptual imagination of nebulous entities like global civil society or the infosphere are predicated on the now quite marked tendency towards the 'unbundled' transformation of what Marvin and Graham refer to as the "modern ideal'31 of integrated, monopolistic, publicly-owned large-scale technical systems, themselves the product, in many respects of the Fordist era and the organisation of Western societies for total war. ${ }^{32}$ In the words of Keller Easterling, infrastructures today form a set of 'Teflon-coated spatial [and temporal] products' with an ambiguous relationship to the stateform, and which, in particular, facilitate the smoothing out of the logistical pathways of commodity circulation across the planet. ${ }^{33}$

Infrastructures have, in general - and not without reason, tended to be analysed as large-scale technical systems. And although that situation is changing - with a lot of interesting work undertaken by historians and
28. Paul N. Edwards, 'Infrastructure and Modernity: Force, Time, and Social Organization in the History of Sociotechnical Systems' in Thomas J. Misa et al (eds), Modernity and Technology, Cambridge, MA, MIT Press, 2004. (Hereafter Infrastructure and Modernity).

29. Bruce Mau, quoted in Stephen Graham, Disrupted Cities: When Infrastructure Fails, London, Routledge, 2009, p7.

30. David Landes, Revolution in Time: Clocks and the Making of the Modern World, Cambridge, Harvard University Press, 1983.

31. Stephen Graham and Simon Marvin, Splintering Urbans. Networked Infrastructures, Technological Mobilities and the Urban Condition, London, Routledge, 2001.

32. David Edgerton has insisted on the indissociability of the welfare and warfare in his Warfare State: Britain, 1920 -1970, Cambridge, Cambridge University Press, 2005.

33. Keller Easterling, Enduring Innocence. Global Architecture and its Political Masquerades, Cambridge, MIT Press, 2007. 
geographers in particular - the predominant, and predominantly technical, framework for considering digital infrastructures is one that tacitly separates out such infrastructures and what they do from questions of subjectivity, in spite of the evident connections between the two. When a technical infrastructure is analysed in terms of the manner in which it addresses a functional, societal need, for example, that issue about the nature of subjectivity is kicked into the long grass of 'need'. But this kind of bifurcated thinking, turning a de facto distinction into something more akin to a de jure separation, can make it very difficult to understand the ways in which digital infrastructures form a constitutive element of experience, folding together subjectivity and domains that might more normally be considered cultural, even psychological (anxiety) with more or less successful technical processes, operations and arrangements. Historians such as Wolfgang Schivelbusch or Stephen Kern have nonetheless had little difficulty in tracing the links between infrastructure and experience, and whilst there is now an abundant literature exploring the fluidity of networked experience (the unintentional irony of characteristic modernity in terms of its liquidity), there's never much exploration, other than in terms of vague macroeconomic or epochal generalisations, of how such fluidity is constituted. Critical thinking is, as a result, left strangely disarmed when it comes to addressing the implication of technical practices within politics, and a fortiori, the links of processes and practices of automation with anxiety and other forms of agitation. Here it is, we might say, the issue of 'getting a hold' on capitalism that is at stake.

\section{INFRASTRUCTURE AS POWER RELATION}

Whilst it is in many respects correct to consider the processes and practices of automation that work to constitute digital technologies as infrastructures in terms of the province of very particular and often very exacting forms of technical expertise, it will be difficult to understand the broader logic of automation if we continue to think along the lines, not just of cast-iron divisions between technical and other forms of practice, but also in terms of a theoretical discourse that presumes that division in the first place. To be sure, as earlier sections of this paper have suggested, the professional expertise of the emerging fields of computer science, software engineering and so on, has been a critical element in the constitution of the digital infrastructures of the present, but processes and practices of automation have extended beyond specifically professional expertise for some time. In part, the peculiar compact between state and professional expertise traced out by Balogh and others had broken down by the 1970s and a new regime of knowledge production emerged, allied to a different presentation of scientific practices, now framed in terms of the more openly commercial terms of the knowledge economy.

Of course, the commercialisation of the internet, the emergence of new media work and the enormous growth in the use of, for example, mark-up 
languages, has in turn made the boundary between professional expertise in programming and other forms of practice much fuzzier. Certainly, one can argue - as STS scholars might - that the work of, say, computer programmers is never exclusively technical, and that automation has never been about the imposition of technological form on human content. All of that is doubtless true. But the more significant point is in fact that much of the work that other actors do, is itself or has itself become technical or incipiently so, even where it might not appear such. Digital technologies do not operate in an unstructured environment: processes and practices of automation do not only presuppose the stabilised phylum of digital technological and other infrastructures. They also presuppose a more or less 'patient' social and cultural environment within which they can operate. The predominance of a representational understanding of software - in which it mathematically models the world as information, which users then simply exchange - all too easily overlooks the grey area in which processes and practices are translated into material-semiotic forms that are tractable to computation. Some of this translation happens within software, but some of it happens in the routinised, quasi-formalised, rule-governed regularisation of the non-computational. The military and corporate contexts in which the processes and practices of digital technological automation, generating 'algorithmised people' emerged testify to the importance of the regimented, highly regular nature of context, but in a world to be constituted by the programming of digital technological infrastructures, we all, to some extent, think and act like programmers. Structuring the environment for the ongoing work of automation, even if this is only in the manner in which users learn to 'repair' the errors that digital technology makes, is a highly distributed activity. However it is something that also gets overlooked a bit too easily in the metonymic discursivisation of processes and practices of automation as the 'algorithmic' imposition of form on content: indeed framing matters in these terms is largely to subscribe to the discursive terms of Science as elaborated earlier in this paper.

The successful functioning of an algorithm presupposes inputs and outputs structured as data, which in turn implies a segmented conforming of the actions of people and things to the specific organisation of the technology (140 characters maximum, this is how you scan a bar code, keyword search, look straight at the camera, and so on). It is not simply a matter of 'representing' things, people, processes, as information. This computer scientific way of presenting the issue is not incorrect, from a mathematical point of view, but it is remarkably selective in what it pays attention to. Rather it is a question of shaping processes of enunciation (in a very broad sense) to adapt to technology. Research in the field of 'cultural techniques' offers a way of understanding some kinds of proto-technological behaviour of this kind, as does the historically close fit of software with already well-formalised business processes and practices. But rather than arguing here without hesitation in favour of the functional efficacy of IT (it's used because it does what is wanted, 
34. Michel Foucault. 'The Subject and Power' afterword to Hubert L. Dreyfus and Paul Rabinow, Michel Foucault. Beyond Structuralism and Hermeneutics, Hemel Hempstead, Harvester Wheatsheaf, 1982, pp224, 227.

35. Andrew

Barry, 'Lines of communication' in Graham Burchell et al (eds), The Foucaul Effect, Chicago, University of Chicago Press, 1999, p128. it is transparent to intentions, it meets a pre-existing need) it would be just as plausible to argue the contrary, to say that it is in fact the very material rigidity of computation, its obstinate recalcitrance to intention, particularly in its early years, that is most suggestive of its conformative efficacy: 'talking' to a computer has always meant learning how to adapt to its inflexibility, especially when the clunky crudeness of the machine or very high levels of financial cost dictated, in the workplace. It is important to acknowledge these kinds of sometimes small, sometimes much bigger, shifts and transformations that take place around digital technology, to acknowledge that in the background, the use - and utility - of machines doesn't exist independently of the processes through which subjectivation happens.

Framing processes and practices of automation in these terms is not just about questioning the distinction between technical and non-technical practices, but by moving beyond the representational presentation of digital technologies in terms of the idea of mathematical models of the world, and by questioning the tacit self-evidence of use and utility, it becomes possible to open up a level of analysis that one could quite reasonably term microphysical or micropolitical, since it is constituted at the uncertain limits of an historically specific set of power relations. It raises questions about how bodies are explicitly or implicitly invested by digital technological infrastructures, or processes of infrastructuring (to highlight the relational quality) because they are indeed invested, in one way or another, by automation, from the outset.

Referring to power relations is, of course, a way of bringing Foucauldian ideas, specifically about governmentality, more explicitly into the picture that is being painted here of automation. It is, precisely, in terms of governmentality that Foucault comes to frame his conceptualisation of power as a "way in which certain actions may structure the field of possible actions' 'modes of action upon possible action, the action of others' and so on. ${ }^{34}$ But one might reasonably ask what sort of governmentality operates across digital infrastructures? Is it true that digital technological infrastructures facilitate forms of action at a distance in a manner akin to the 'technologies of freedom' that Foucauldian scholars in particular have associate with the governmental practices of the nation states of nineteenth- and early twentieth-century liberalism? When, as Andrew Barry has put it, 'communications infrastructures came to function as perfect embodiments of the liberal political imagination: maximising the density, intensity and spatial extension of interactions within the social body itself while, at the same time, minimising the direct demands made by the state on the people'. ${ }^{35}$

\section{A NEW FORM OF GOVERNMENTALITY?}

It's not at all clear that contemporary digital infrastructures work through a relation to substantially independent individuals addressed as if endowed with a capacity to 'judge for themselves', or, indeed that the complex organisation 
of surveillance and regime of generalised traceability now associated with global flows of information, has anything very liberal about it. On this point, Deleuze and Guattari's arguments concerning the 'automation and autonomisation' of the war machine in the post-war era of organised (in)security, developed by Éric Alliez and Maurizio Lazzarato in terms of an analysis of the 'global war machine of capital', is perhaps better attuned to the functioning of power relations across digital infrastructures, than the more human-scientific analytic focus of Foucauldian governmentality studies. The automation and autonomisation of the war machine in the Cold War era points directly, albeit allusively, to precisely the emergent information technological managerialism discussed earlier in this paper and its geopolitical presuppositions, linking the kind of dynamics usually considered to operate 'endogeneously' under the rubrics of 'the' technological and 'the' economic, into direct connection with shifting forms of knowledge and expertise. But more interestingly for the purposes of the present discussion, perhaps, it brings into play a specifically machinic vocabulary for the analysis of automation, one which Alliez and Lazzarato (the latter in particular) have developed for understanding the extensive investment in the complex grey areas where the boundary between technical machines and human subjects becomes blurred. A key aspect of a form of governmentality which operates through technology, '[machinic] enslavement, Lazzarato puts it in Governing by Debt, does not work with 'subjects' and 'objects', it works on their deterritorialisation (or their decodification), that is, with the molecular components, the non-individuated intensive, subhuman potentialities of subjectivity and the non-individuated, intensive, molecular component parts and potentialities of matter and machines' ${ }^{36}$ Employing additionally Deleuze's notion of dividuality, Lazzarato further points out that under conditions of 'enslavement' human agents not only form part of a broader machinic assemblage, in which the usual oppositions between human and machine break down, but further that 'the component parts of subjectivity (intelligence, affects, sensations, cognition, memory, physical force) are no longer unified in an 'I', they no longer have an individuated subject as referent. Intelligence, affects, sensations, cognition, memory, and physical force are now components whose synthesis no longer lies in the person but in the assemblage' (Governing by Debt, p188). The matter of whether or not there ever was a substantially independent autonomous subject, an 'I' that unified the component parts of subjectivity is moot, but the point is a political one: power relations as operative across infrastructures don't find as their unifying point of integration the citizen of the liberal democratic polity but imply instead a 'user' envisaged from within digital technologies as a very precisely specified set of capacities for interacting with machines.

Linked by Lazzarato to Foucault's arguments about security as the organisation of a milieu, the governmental role of machinic enslavement is evidently connected with the slow emergence of digital technological infrastructures in the post-war era, the emergence of administrative
36. Maurizio Lazzarato, Governing by Debt, Los Angeles CA, Semiotext(e), 2015. (Hereafter Governing by Debt). 
37. Karin Knorr Cetina and Urs Bruegger, 'Inhabiting Technology: The Global Lifeform of Financial Markets', Current Sociology, 50, 3, 2002, pp395, 396.

38. There are evident parallels here with Gilbert Simondon's work on individuation. governance and the managerialism associated with information technology. Curiously, one of the earliest points of emergence of this 'milieu', presenting dramatic confirmation of the machinic effects it entails, is provided by trading in finance markets. Karin Knorr-Cetina's research on what she calls the 'temporally constituted screen world' 'inhabited' by traders looks a great deal like the machinery producing subjectivity in Lazzarato's account of machinic enslavement, wherein 'money, stock prices, the spread, algorithms, and scientific equations and formulas constitute semiotics that make the capitalist social machine function in view of both valorisation and the production of subjectivity' (p189). For Knorr-Cetina, informed by the phenomenological sociology of Alfred Schutz, what is constituted through the screen is in fact a "world' "not simply a "medium" for the transmission of messages and information. It is a building site on which a whole economic and epistemological world is erected' as a consequence of 'what appears to be a total immersion in the action in which they [the traders] take part'. ${ }^{37}$

There are clearly differences between the organisation of the screen world of traders and the broader investments of a governmental apparatus and it is important not to forget that in the account Lazzarato offers, machinic enslavement is one component of contemporary governmentality as he understands it (the other being subjection, subjectivation of the kind that operates through discursive interpellation). It's also important not to slip back into the ironic stance of mass culture critique, which is never far away when we talk about others and their relationship to the machinery of the culture industry. In the present context, this is a risk which presents itself in particular when the emphasis is on human-machine systems as alreadyconstituted, complete entities, when, that is, one takes as a given what is in fact only a cybernetic/informatic/technological ideal. Certainly - and Knorr Cetina's work confirms this - the captivating effects of machinic enslavement are very real, but not all configurations of digital infrastructures attain a similar degree of immersive completeness. Contrast, in this respect, computer games, social media platforms and email, for example. Nor are all forms of digital infrastructure produced in the same way as the technology for traders. More mundane, and widespread, practices such as setting up a blog, configuring a CMS, or using the API of a social media platform for the purposes of data gathering are quite different to the work of programming in finance.

Remaining with the question of the production of subjectivity, in relation to processes and practices of automation, it is to the more directly micropolitical dimension of analysis that we must turn. For if it is not simply to become a generic, catch-all term that replicates generic and generalising claims about (cybernetic) human-machine systems, the concept of machinic enslavement requires us to consider more directly the ways in which digital infrastructures invest bodies and their propensities, their habits, drives, and so on. ${ }^{38}$ Experience in digital infrastructures then becomes a crucial datum in a concern, less with the functional effects of new forms of subjection, and 
more with the processes through which assemblages take shape, opening up or closing down possibilities for concrete transformation. ${ }^{39}$ Here, and following instead Guattari, it is crucial to insist that the production of subjectivity is something that operates at an existential pathic level. The idea of 'pathic subjectivation' that Guattari develops in his later writings and the modularised conception of 'partial enunciation' that he associates with it extends the logic of non-discursive intensities and the pluralisation of semiotics that formed such a key part of his work with Deleuze. ${ }^{40}$ Reference to the 'pathic' brings aesthesis, the incessant mobility of sensing, as the phenomenologist Renaud Barbaras has put it, into view as a key element in the production of subjectivity. ${ }^{41}$ From the point of view of addressing processes and practices of automation, it draws our attention precisely to the constitution and configuration, the cartographic complexity of the affective textures of infrastructural experience, a complexity that becomes difficult to apprehend when one turns to generic ideas about information flow and exchange, for example. Here, the relevant datum is not what Edwards articulated as the sense of stability, the grounds on which people sense that society 'works', because this sense of permanence, the 'modern ideal', is well on the way to disappearing. Rather, it is the impermanence and fragility, the decomposition of the social and cultural forms that digital infrastructures parasite and the demented production of software to sit between the global 'space of flows' and the populations that produce those flows that becomes relevant. What matters is less the seamless integration of users into systems and more the dynamics generated through the fragmented patchiness and lack of 'interoperability', constant processes of software updating, the stupidity and ineptness of systems, the refusal to standardise, the increasingly carefully policed terms on which one can engage with a technology (Zittrain's tethering) - and everything one is obliged to do to correct such failings, 'repair' work, 'articulation' work, 'junction' work, and so on. Such features of processes and practices of automation are usually presented as negligible contingencies, something that is probably true from the statistical point of view that informs the commercial strategies of technology companies. But they are certainly not negligible from the point of view of the logic of automation in digital infrastructures. Digital infrastructures are not a complete milieu, not a seamless infosphere, they exist alongside other strata constitutive of society or culture, and in this respect effectively generate disorientation and ambiguity, amplifying discordances within practices, between systems (or specific universes of reference, to use Guattari's terms), dismantling the existential territories of everyday life, generating new loci and processes of enunciation (the investment of the hand and its gestural capacities), and so on.

Susan Leigh Star, a well-respected scholar of infrastructures, (and someone hardly suspect of Guattarian leanings) has, with Karen Ruhleder, drawn on Bateson's notion of the double bind and the schizophrenising problems

39. It's worth noting in passing that Lazzarato does insist on the importance of what might be called 'institutional praxis' in his work.

40. Félix Guattari Chaosmosis Sydney: Power Institute, 1995 , chapter 4 .

41. Renaud Barbaras,'Life, Movement, and Desire', Research in Phenomenology, 38, 2008, pp3-17. 
42. Susan Leigh Star and Karen Ruhleder 'Steps toward an Ecology of Infrastructure: Design and Access for Large Information Spaces', Information systems research, 7, 1, 1996, pp111-134.

such double binds can generate, to sketch out a phenomenon they refer to as 'infrastructural transcontextual syndrome' to account for the problems generated through the conflict created in digital infrastructure design and deployment in an organisational context. ${ }^{42}$ Exploring the challenges of developing information infrastructure for scientific practices in the early 1990 s, they were interested in 'barriers to use', why it was that particular systems failed to achieve the widespread adoption that might allow one reasonably to talk about an infrastructure. When a design flaw in a system can be interpreted as user error, for example, or when the knowledge context of designers is presumed as necessary but is unavailable to users ('you just need to FTP the file ...'), we are in the realm of the double bind. Being situated in very different contexts, with little commonality, the practices of system designers and system users were ripe for the generation of confusion. Interestingly, for Leigh Star and Ruhleder, one can only really start to talk about the successful 'infrastructuring' of an IT system once double binds of the kind they outline are resolved. Without this happening, they argued, it is difficult for automation, or automatism, to occur.

And yet, germane though Star and Ruhleder's account is for understanding the contingencies of digital infrastructural automation, technology development subsequent to the early 1990s has seen a fairly systematic shift in how infrastructures, infrastructuring, is achieved. Not through the kind of nuanced and sensitive dialogue between different communities of practice, between system designers and system users, that they called for, but rather in terms of a progressive automation of many of the processes - installing an operating system, for example - through which users would otherwise have come into contact with technical universes of reference. But one cannot for all that say that disorientation and ambiguity have thereby disappeared, or double binds of the kind tracked by Star and Ruhleder been resolved.

\section{CONCLUSION: GETTING A HOLD?}

Ending this discussion of automation anxieties with a brief set of references to the disunified, disorganised nature of digital infrastructural experience, and what might seem to be failures in processes and practices of automation is not accidental. Commentators, both for and against, have a marked tendency to present this experience in remarkably coherent, unitary terms, whether they are eulogising over friction-free flow or human-machine cybernetic enslavement. But this, as has been pointed out, is to risk taking a theoretical ideal for reality. Why present matters in this way? Why blur the distinction between technical and non-technical practices and insist on inserting processes and practices of automation into the relational fabric of power, rather than present automation in more conventionally politicaleconomic terms? And why draw attention to the complexities of contemporary digital infrastructures? In part, this is simply about an empirical insistence 
on the way that automation happens and avoiding the trick of theories that make seemingly interesting political claims on the basis of overly simplistic abstractions. If digital technological infrastructures are part of an historically specific organisation of power relations, and if processes and practices of automation are an important aspect of the contemporary production of subjectivity, one can't simply view the political challenges that they present as one of simple 'reappropriation' or, indeed, acceleration. Digital infrastructures are marked by asymmetries of power. Not irreversibly so, perhaps, but certainly in such a manner as to complicate considerably the manner in which one might seek to understand the growing hold of planetary computation. What is needed are forms of analysis that build on the resistance that is located, albeit in highly ambiguous forms at the uncertain limits of power, in the complex fabric of human-machine relations.

Andrew Goffey is Associate Professor in Critical Theory and Cultural Studies in the Faculty of Arts at the University of Nottingham. 